\title{
Application of the TOF-SIMS and SEM-EDS methods to assess the influ- ence of dusting from a phosphate waste deposal place based on hair analysis
}

\author{
Małgorzata Iwona Szynkowska, Ewa Leśniewska, Aleksandra Pawlaczyk, Jacek Rogowski, Tadeusz \\ Paryjczak
}

Technical University of Lodz, Department of Chemistry, Institute of General and Ecological Chemistry, Żeromskiego 116, 90-924 Lodz, Poland

\begin{abstract}
In this work, scanning electron microscopy with energy dispersive X-ray spectrometry (SEM-EDS) and the time-of-flight secondary ion mass spectrometry (TOF-SIMS) were used to study the particles present on the hair surface of the inhabitants of Wislinka (people environmentally exposed due to the closeness of a dump) in order to obtain the information about the possible influence of dusting from a phosphate waste deposal place. Additionally, the morphology and the composition of fresh phosphogypsum were analyzed. Waste phosphogypsum is formed in the process of a wet phosphoric acid production and there is still a problem with its storage. A thorough understanding of the composition and chemistry of phosphogypsum seems to be necessary to evaluate its environmental impact comprehensively. The results obtained from these two techniques turned out to be complementary and revealed the information expected.
\end{abstract}

Keywords: phosphogypsum, surface analysis, hair, SEM-EDS, TOF-SIMS.

Presented at VII Conference Wasteless Technologies and Waste Management in Chemical Industry and Agriculture, Międzyzdroje, 12 - 15 June, 2007.

\section{INTRODUCTION}

It is well known that hair analysis can be useful in assessing occupational and environmental exposure to toxic substances. Hair investigations can also provide valuable information concerning the use of certain drugs. Many studies indicated that hair samples could efficiently accumulate elements. It is generally connected with the presence of cysteine, which builds up hair structure up to approximately $14 \%$. Many metals are bonded to sulphur atoms in cysteine or to sulphydryl (SH) groups existing in other amino acids. Metals can be linked with various functional groups like basic, acidic and peptide bonds. They can also make up to the hair structure by melanin, which influences hair color and interacts through ionic interaction. This ionic bond can also be achieved, for example van der Waal's interaction. In the case of uncharged metals like elemental $\mathrm{Hg}$, the linkage can be enhanced by the hydrophobic core of the melanin polymer in the hair structure. To make hair analysis more reliable, the nature of the binding of exogenous elements to hair needs to be thoroughly investigated. Recent researches focus on the analysis of attached particles deposited on different biological indicators pointed out a direct relation between the state of the surface of the samples investigated and the condition of the environment. They were also applied to assess local airborne toxic elements contamination throughout the dusting process. Hair samples can be used as such indicators, but it should be stressed that they are difficult material to carry out that kind of investigations ${ }^{1-3}$.

The main aim of this paper was to obtain comprehensive information coming from the SEM-EDS and TOF-SIMS techniques on the chemical composition and the chemistry of phosphogypsum in relation to the particles found on hair samples taken from the inhabitants of Wislinka, living in the close vicinity of a phosphate waste deposal place.

\section{MATERIAL AND METHODS}

The material investigated consists of fresh phosphogypsum and hair samples (50) collected from the people exposed to dusting from a phosphate waste deposal place in Wislinka/ near Gdansk. Approximately $200 \mathrm{mg}$ of human hair from the nape of the neck were taken using stainless steel scissors (the first $3-4 \mathrm{~cm}$ closest to the scalp were used). Hair samples were not washed in order to observe exogenous particles on their surface. The material studied was characterized by the SEM-EDS and TOF-SIMS methods. The morphology of the samples was analyzed by means of the SEM-EDS, a scanning electron microscopy with field emission S-4700 Hitachi (Japan) equipped with the energy dispersive spectrometer Thermo-Noran (USA). The EDS method made it possible to obtain maps of elemental distribution on the chosen microarea. Before the SEM-EDS measurements the samples were placed on carbon plasters and coated with the use of carbon target by the Cressington $208 \mathrm{HR}$ system. The accelerating voltage was $25 \mathrm{kV}$. The EDS spectrum and the maps showing elemental composition and surface distribution were collected from the SEM pictures and additionally from single points at magnification $\times 1,500$. The TOF-SIMS measurements (positive and negative spectra and images) were carried out using the IONTOF instrument (TOF-SIMS IV, Germany) equipped with $25 \mathrm{keV}^{69} \mathrm{Ga}^{+}$primary ion gun and 2,5 pA pulse current. In order to perform the analysis, single hair samples were placed on a special steel plate. Both ends of the hair sample were fixed by two screws on each side of the steel plate. In the case of fresh phosphogypsum, samples were pressed into tablets before the measurements to obtain better mass and lateral resolution.

\section{RESULTS AND DISCUSSIONS}

So far the exact mechanism involving the incorporation and uptake of elements and substances in the hair matrix has 
not been clearly understood. Few papers provide information connected with specific localization and distribution within a hair ${ }^{3}$. In order to understand the impact of a phosphate waste deposal place on the elemental content of hair collected from the people living in the vicinity of a dump, two suitable techniques (SEM-EDS and TOF-SIMS) for detecting and analyzing the possible existence of particles present on the surface investigated, were applied. The SEMEDS analysis can be performed on the submicrometer particles but it only reveals elemental composition with a potential detection limit of $0.1-0.5 \mathrm{wt} . \%$ for most elements. The TOF-SIMS method delivers elemental and molecular information from one to three monolayers of a studied material surface, and on the other hand, strongly depends on $\mathrm{Ca}_{10}\left(\mathrm{PO}_{4}\right)_{6} \mathrm{~F} 2+10 \mathrm{H}_{2} \mathrm{SO}_{4}+20 \mathrm{H}_{2} \mathrm{O} \rightarrow 10 \mathrm{CaSO}_{4} \cdot 2 \mathrm{H}_{2} \mathrm{O}+6 \mathrm{H}_{3} \mathrm{PO}_{4}+2 \mathrm{HF}$ (phosphate rock)

(phosphogypsum)

Figure 1. The reaction of the gypsum by product formation in the wet phosphoric acid process the matrix (especially in the case of highly inhomogeneous material). The phosphogypsum studied contains $\mathrm{CaSO}_{4} \cdot 2 \mathrm{H}_{2} \mathrm{O}$, which is a major component. In fact, additional ingredients of this by-product are dominated by a variety of impurities, like fluorine, silica, phosphorus, heavy metals, trace elements, rare earth elements or naturally occurring radionuclides ${ }^{4}$. The composition of phosphogypsum varies greatly with different phosphate rock sources. It is a consequence of the fact that the impurities generally originate from the phosphate rock used in the production of phosphoric acid (Fig.1.), which is finally applied in phosphatic fertilizers processing.

Based on the SEM-EDS measurements of fresh phosphogypsum samples, we can observe the surface characterized by a different morphology and chemical composition (Fig.2., Fig.3.). Figure 2 shows an X-ray spectrum collected for fresh phosphogypsum from a SEM picture. The presence
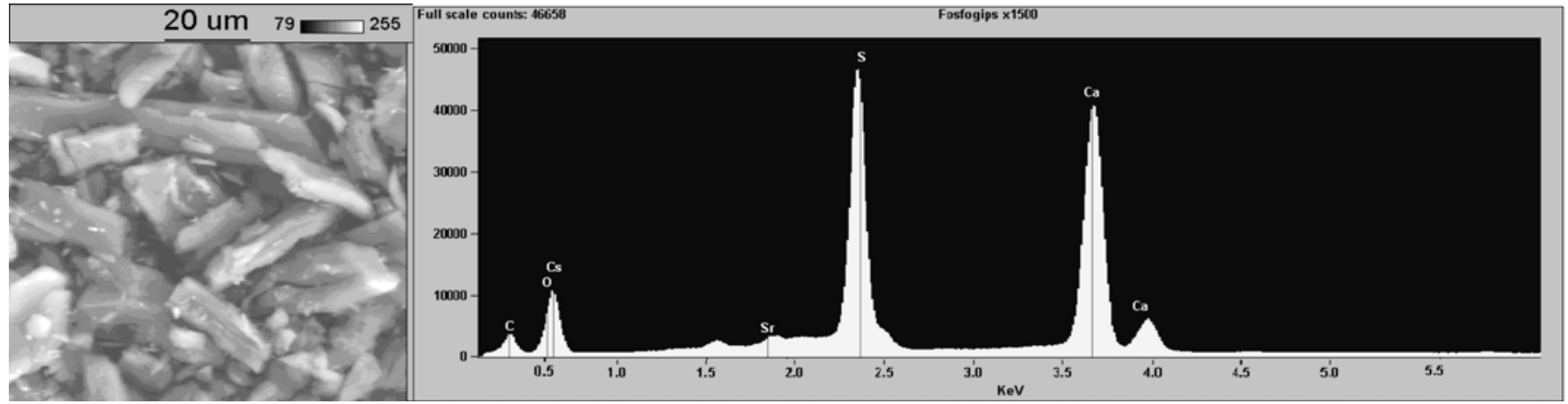

Figure 2. The SEM micrograph of fresh phosphogypsum surface $(\mathrm{x} 1,500)$ and the corresponding X-ray spectrum of fresh phospogypsum $(\mathrm{x} 1,500)$

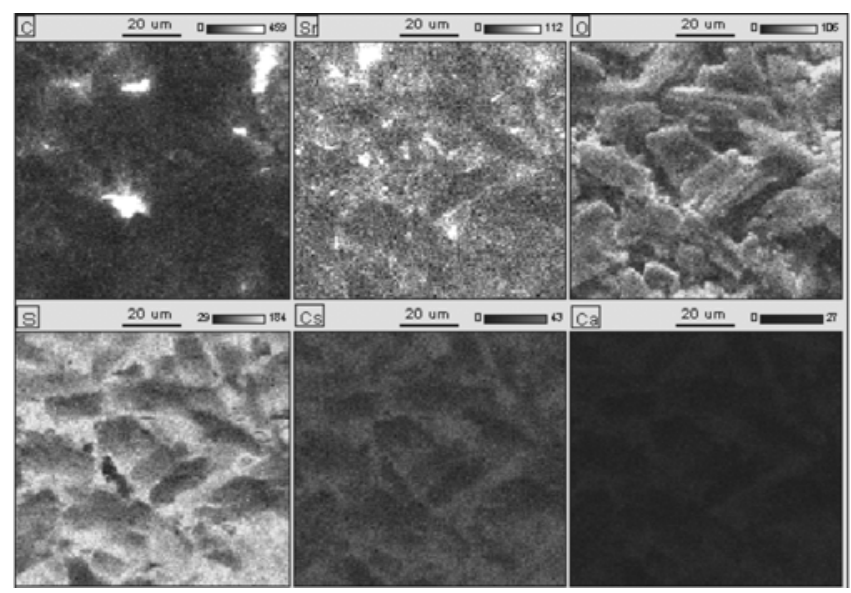

Figure 3. The SEM-EDS images of crystallites and particles on fresh phosphogypsum surface showing $\mathrm{C}, \mathrm{Sr}, \mathrm{O}, \mathrm{S}, \mathrm{Cs}$ and $\mathrm{Ca}$ distribution $(\mathrm{x} 1,500)$ of $\mathrm{S}, \mathrm{Ca} \mathrm{C}, \mathrm{O}$, Cs and $\mathrm{Sr}$ was detected. The highest intensity was noticed for $\mathrm{S}$ and $\mathrm{Ca}$ (main ingredients of phosphogypsum). The distribution of these elements is presented on the maps (Fig.3.). In the case of O, S, Ca Cs, nearly homogenous distribution is observed. For strontium, small particles (light points on the map) are clearly visible on the phosphogypsum surface and they exist as individual grains, which size is about $2-5 \mu \mathrm{m}$.

An additional EDS point analysis was made from a strontium particle (Fig.4.) to prove that these particles contain mainly $\mathrm{Sr}, \mathrm{S}$ and $\mathrm{O}$ and are not correlated with other investigated elements e.g. $\mathrm{Ca}$.

On the basis of the SEM-EDS results for hair samples, we can state that dust particles from the dump have been transported over the distance and are visible on the hair samples. We can generally distinguish several forms of particles present on the hair surface (Fig.5., Fig.6., Fig.7. and Fig.8.). Point
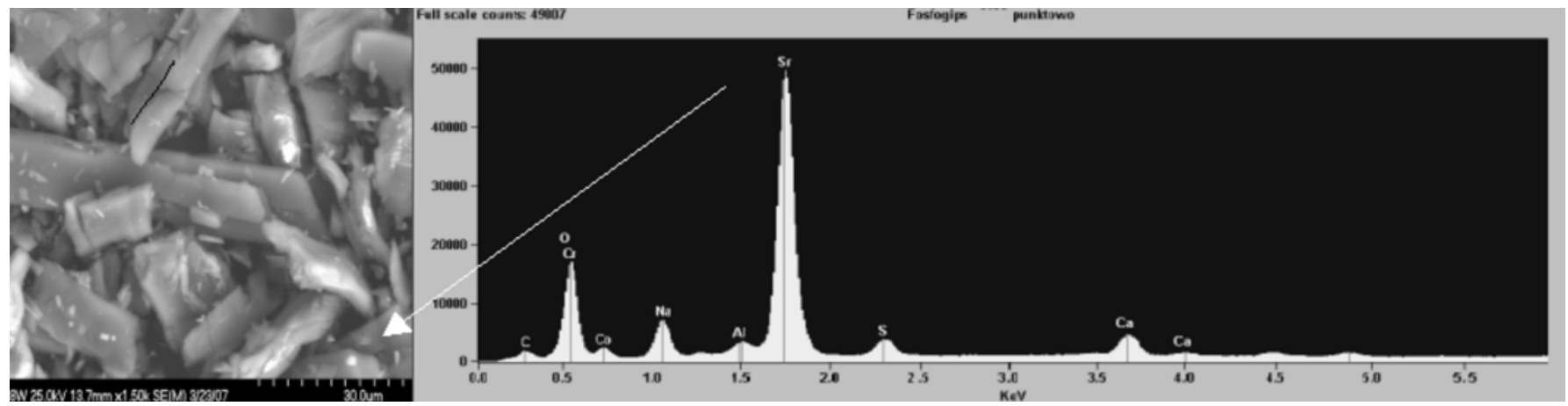

Figure 4. The SEM micrograph of fresh phosphogypsum surface $(\mathrm{x} 1,500)$ and the corresponding X-ray spectrum of fresh phospogypsum collected from a single point 


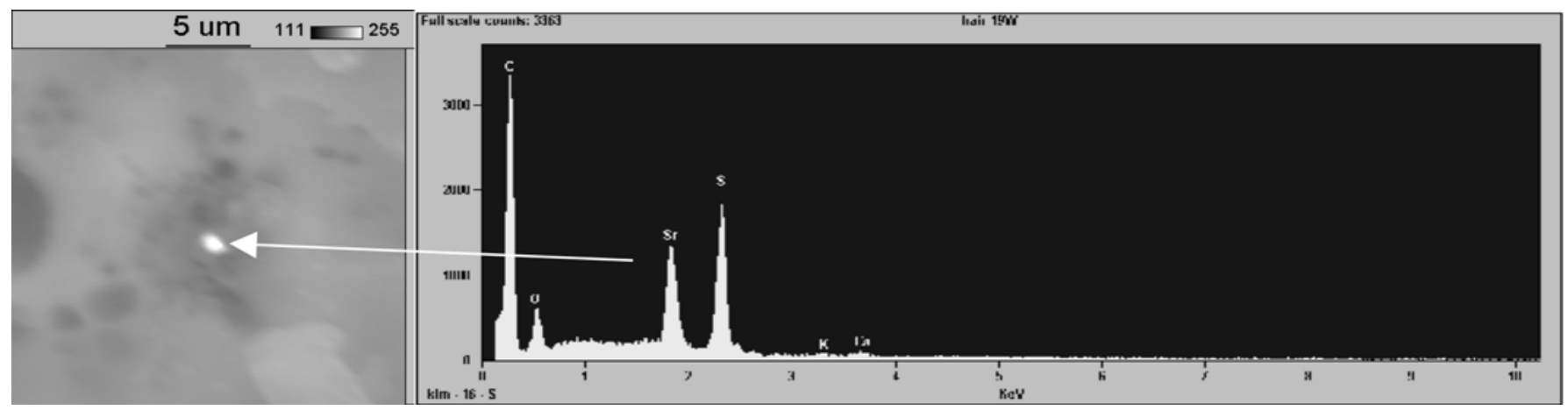

Figure 5. The SEM micrograph of the particles on hair surface $(x 6,000)$ and the corresponding X-ray spectrum of hair (x6,000)
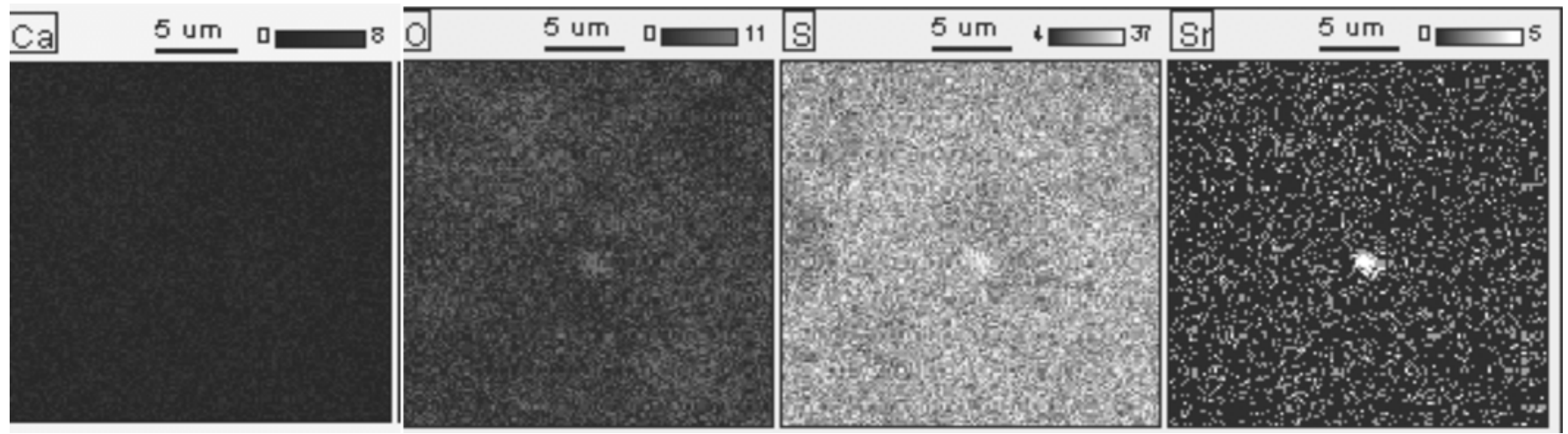

Figure 6. The SEM-EDS images of the particles on human hair surface showing $\mathrm{Ca}, \mathrm{O}, \mathrm{S}$ and $\mathrm{Sr}$ distribution (x6,000)

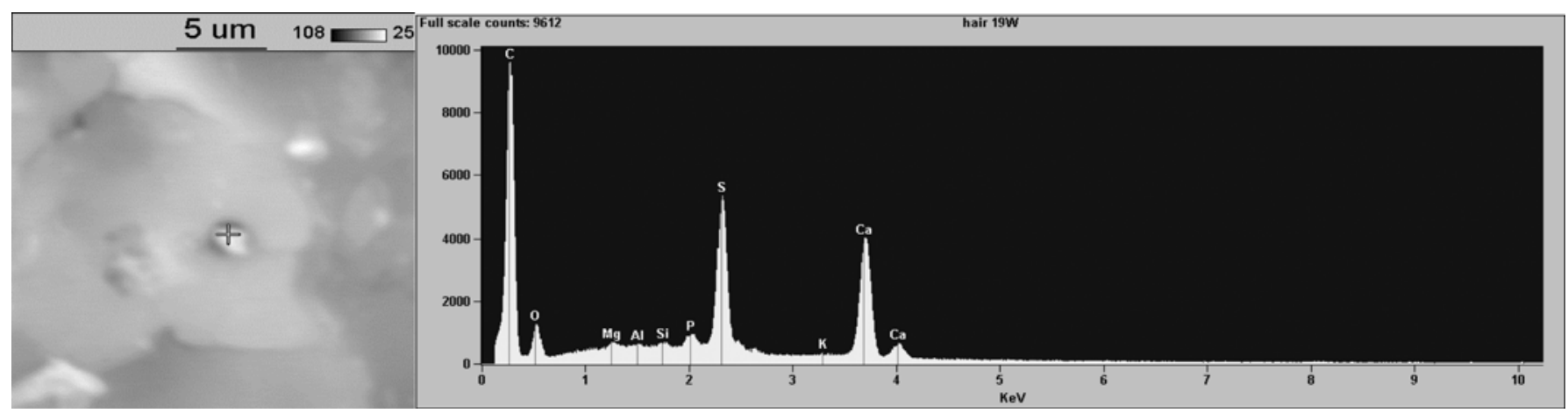

Figure 7. The SEM micrograph of the particles on hair surface $(\mathrm{x} 6,000)$ and the corresponding X-ray spectrum of hair collected from a single point

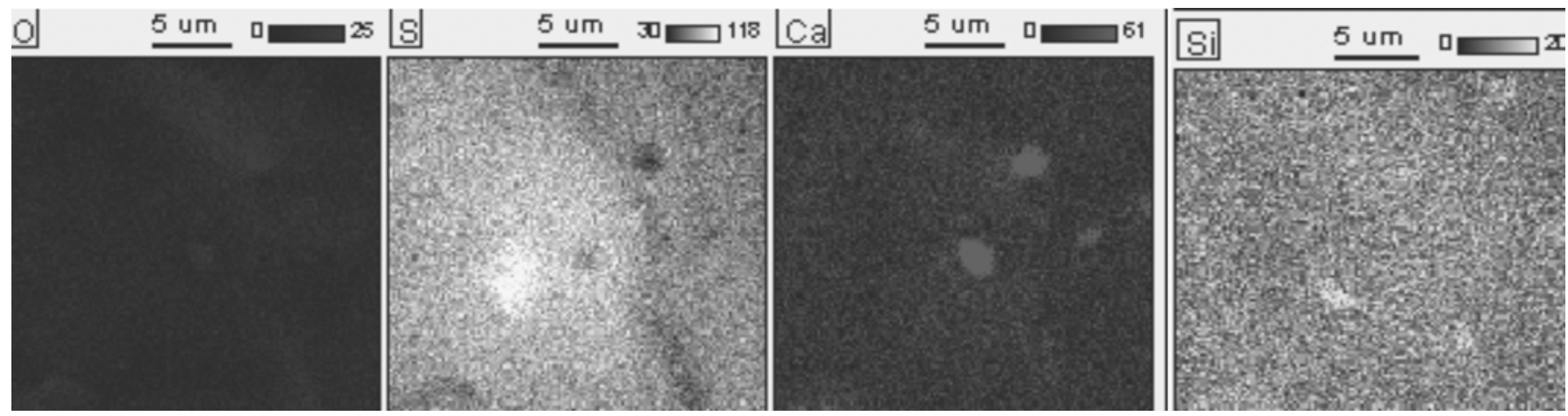

Figure 8. The SEM-EDS images of the particles presented on human hair surface showing $\mathrm{O}, \mathrm{S}, \mathrm{Ca}$ and $\mathrm{Si}$ distribution (x6,000)

analysis (Fig.5., Fig.6.) showed that some of them are very small and contain mostly $\mathrm{Sr}, \mathrm{S}$ and $\mathrm{O}$, which is in agreement with the results obtained from phosphogypsum samples. On the other hand, we can also notice some amount of other particles. They consist of $\mathrm{Ca}$ and $\mathrm{S}$ (two major elemental ingredients of the dump) (Fig.7., Fig.8.).

Figures 9 and 10 show positive and negative TOF-SIMS mass spectra and images of fresh phosphogypsum taken from a field of view $500 \times 500 \mu \mathrm{m}^{2}$. Numerous Sr grains are ob- served on the phosphogypsum surface images (light points) (Fig. 9.), which is in agreement with the SEM-EDS results. Most commonly, the presence of $\mathrm{Sr}$ is strongly connected with its chemistry, which is quite similar to $\mathrm{Ca}$. It is well known that $\mathrm{Sr}$ can substitute $\mathrm{Ca}$ in the gypsum crystal structure. In addition, we can also observe no homogenous distribution of ions like $\mathrm{Ba}, \mathrm{Na}, \mathrm{Mg}, \mathrm{Al}, \mathrm{Si}, \mathrm{K}, \mathrm{C}_{2} \mathrm{~F}, \mathrm{Fe}, \mathrm{La}$ and $\mathrm{Ce}$, found on the phosphogypsum surface. Negative ions 

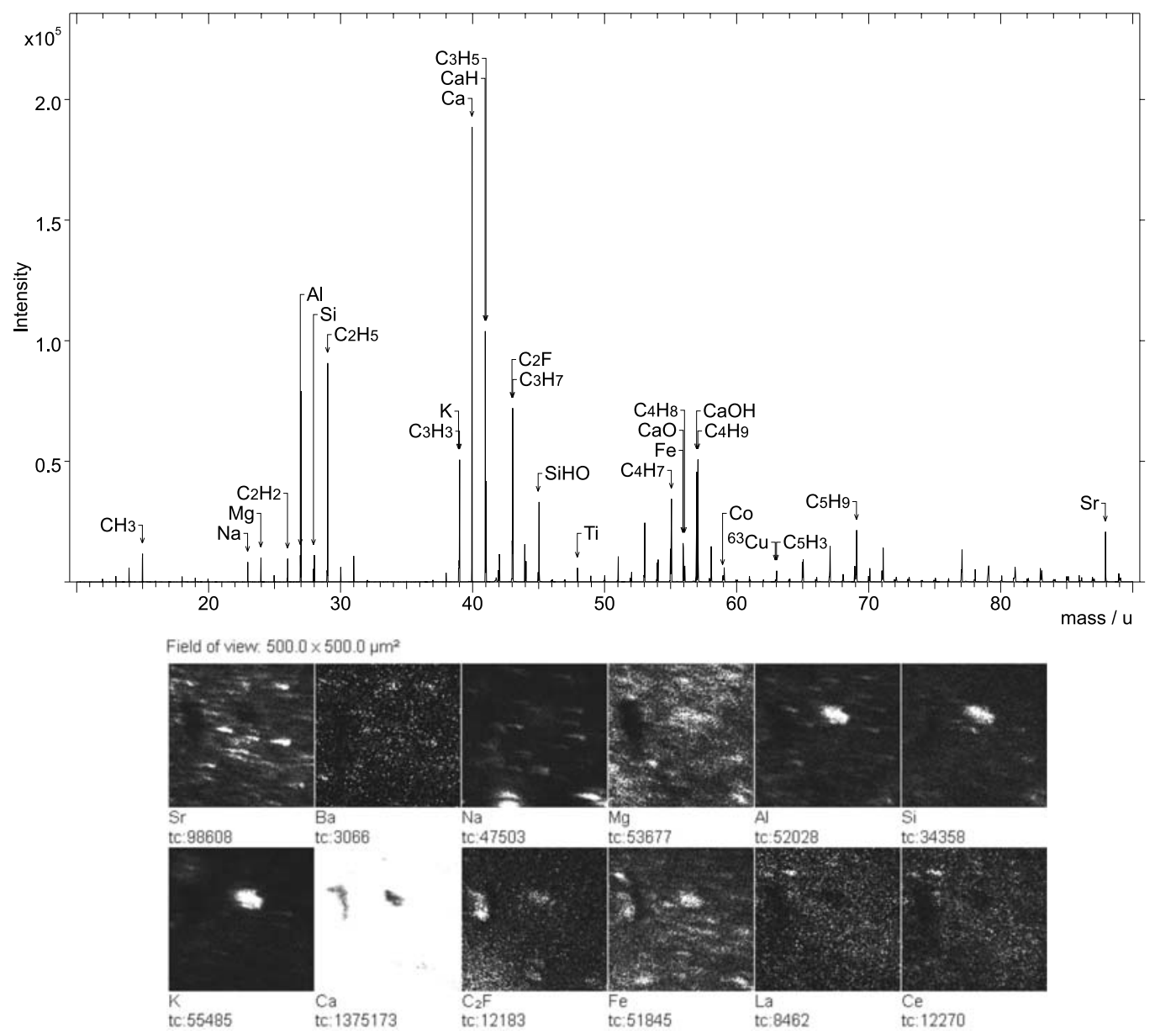

Figure 9. Positive TOF-SIMS ion spectra obtained from phosphogypsum surface and the corresponding images of phosphogypsum showing $\mathrm{Sr}, \mathrm{Ba}, \mathrm{Na}, \mathrm{Mg}, \mathrm{Al}, \mathrm{Si}, \mathrm{K}, \mathrm{Ca}, \mathrm{C}_{2} \mathrm{~F}, \mathrm{Fe}, \mathrm{La}$ and $\mathrm{Ce}$ distribution $\left(500 \mathrm{x} 500 \mu \mathrm{m}^{2}\right)$. Bright colour indicates the investigated ions

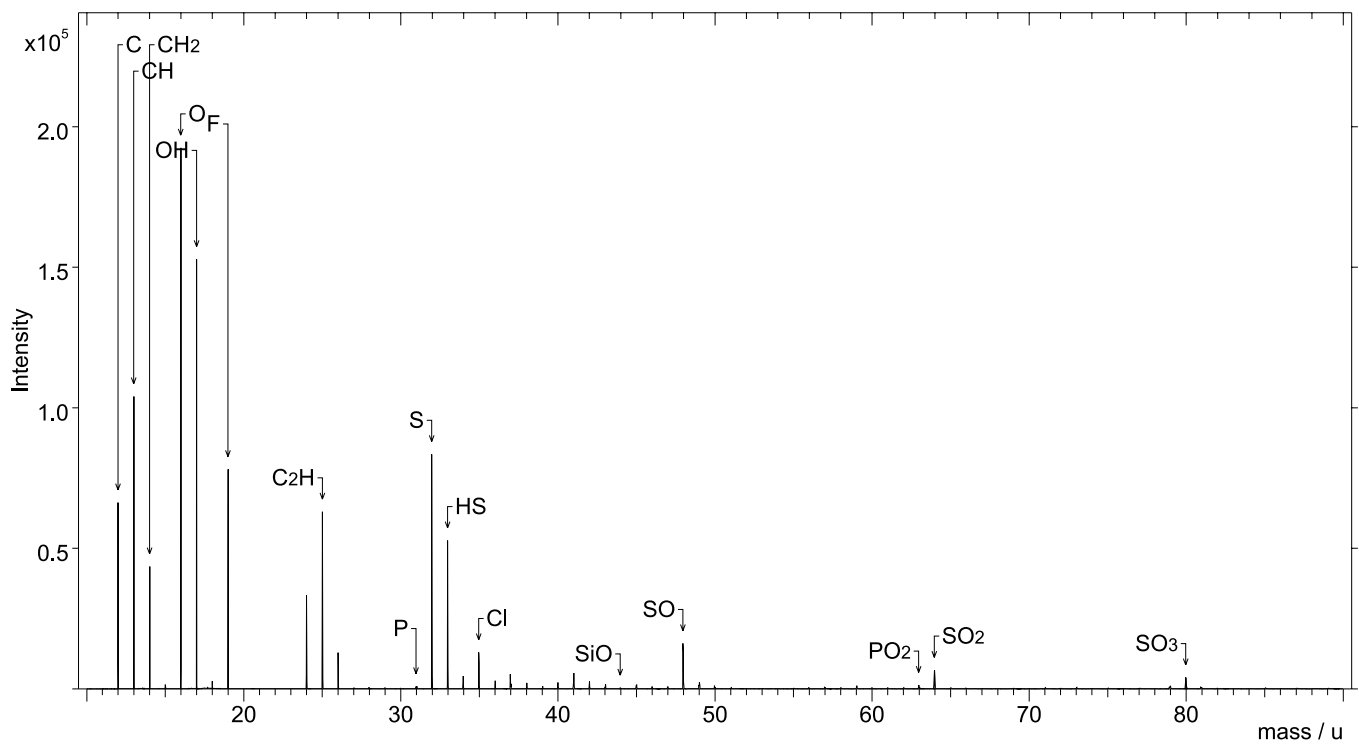

Field of view. $500.0 \times 500.0 \mu \mathrm{m}^{2}$
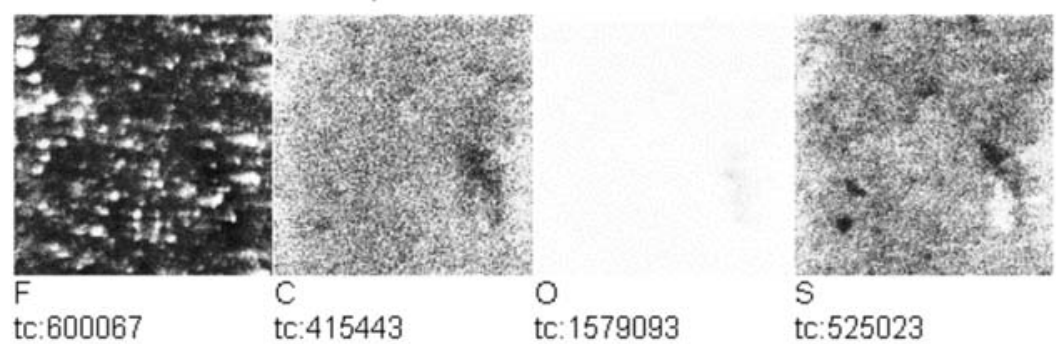

Figure 10. Negative TOF-SIMS ion spectra obtained from phosphogypsum surface and the corresponding images of phosphogypsum showing F, C, O and $\mathrm{S}$ distribution $\left(500 \times 500 \mu \mathrm{m}^{2}\right)$. Bright colour indicates the investigated ions 

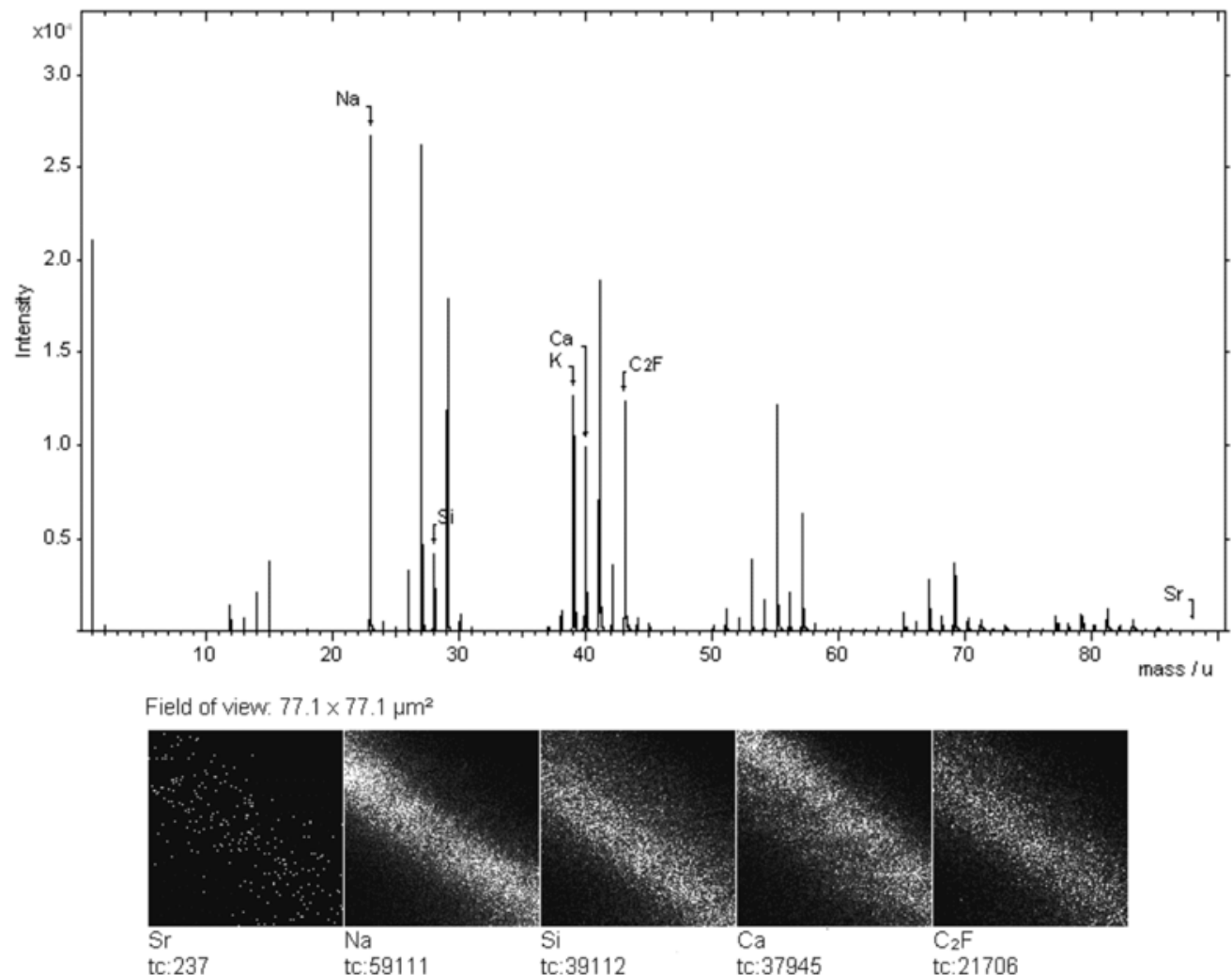

Figure 11. Positive TOF-SIMS ion spectra obtained from human hair surface and the corresponding images of hair surface showing Sr, $\mathrm{Na}, \mathrm{Si}, \mathrm{Ca}$ and $\mathrm{C}_{2} \mathrm{~F}$ distribution $\left(77 \times 77 \mu \mathrm{m}^{2}\right)$. Bright colour indicates the investigated ions

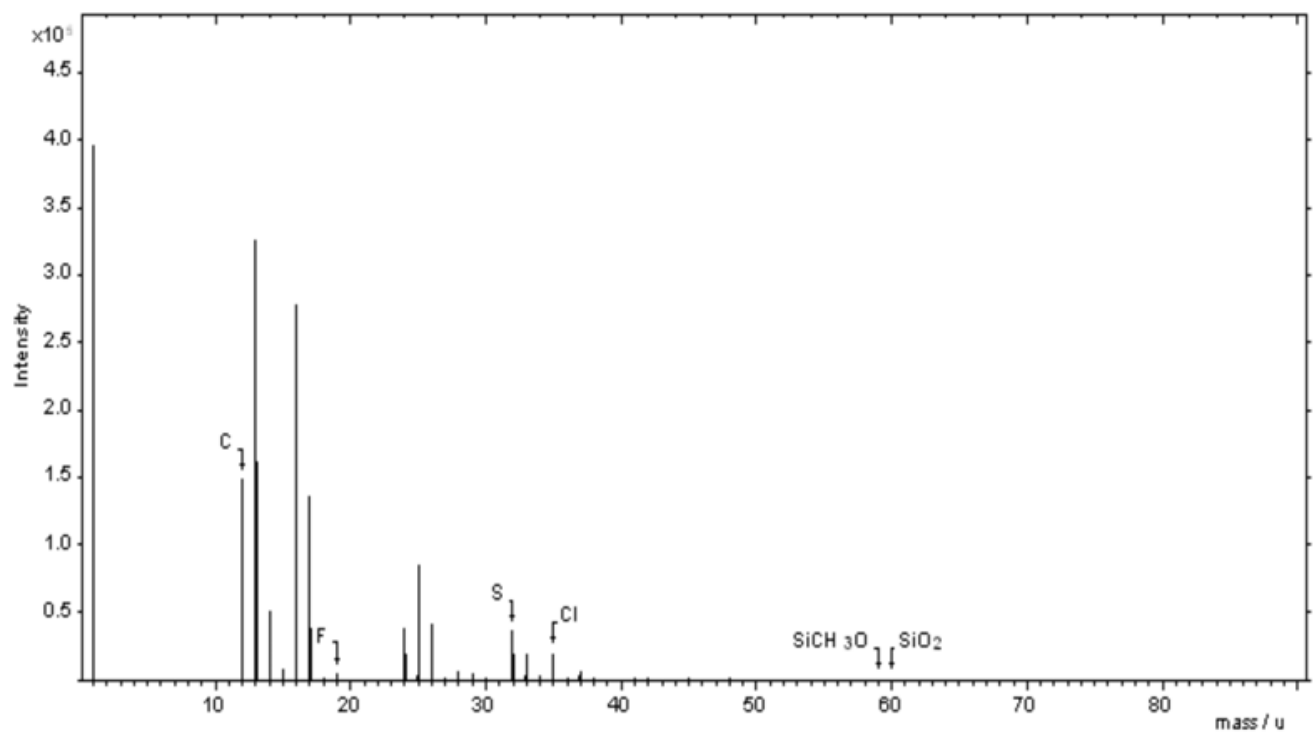

Field of view. $99.6 \times 99.6 \mu \mathrm{m}^{2}$

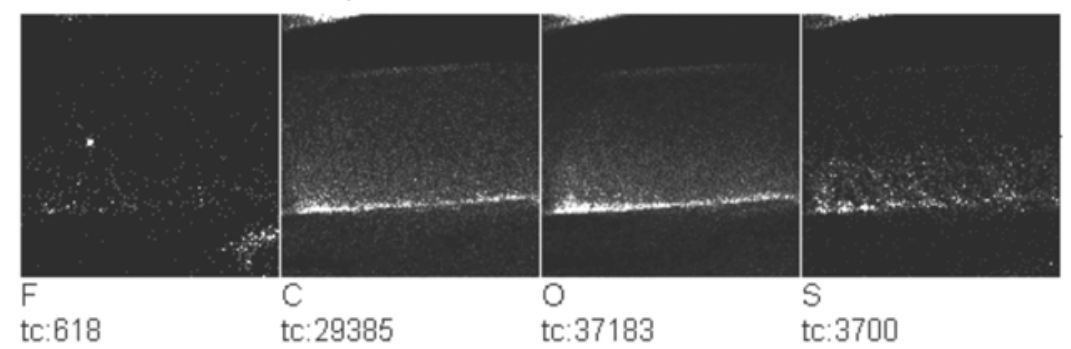

Figure 12. Negative TOF-SIMS ion spectra obtained from human hair surface and the corresponding images of hair surface showing $\mathrm{F}, \mathrm{C}, \mathrm{O}$ and $\mathrm{S}$ distribution $\left(97 \times 97 \mu \mathrm{m}^{2}\right)$. Bright colour indicates the investigated ions 
image (Fig.10.) shows the presence of many $\mathrm{F}$ clusters and some bigger particles containing sulphur.

Hair analysis caused several problems and in the case of the TOF-SIMS measurements, minimalization of the topography and sputter effects are necessary. Figure 11 presents a positive TOF-SIMS mass spectrum obtained from human hair surface and the corresponding image of hair surface showing $\mathrm{Sr}, \mathrm{Na}, \mathrm{Si}, \mathrm{Ca}$ and $\mathrm{C}_{2} \mathrm{~F}$ distribution taken from the area $77 \times 77 \mu \mathrm{m}^{2}$. Sr turned out to be regularly distributed over the hair surface and we could not detect any single grain of Sr. It might have been caused by the fact that small grains containing $\mathrm{Sr}$ are probably built up in the hair structure and for that reason could not be detected by the TOF-SIMS method. Only in the case of fluoride, which is one of the major impurities of phosphate waste, single exogenous particles containing this element are observed on the hair surface (Fig.12.). For other elements, we could not notice any significant anomalies that could be attributed to the influence of a dump neighborhood.

\section{CONCLUSIONS}

The results obtained for hair samples and phosphogypsum using TOF-SIMS and SEM-EDS suggest that these methods can be applied to complementary studies of elemental distribution and the presence of impurities resulting from the production of phosphorus acid. A certain extent of similarity and disparity of the images obtained from both techniques are observed for hair samples. The differences in information coming from these two techniques can be caused by the previously mentioned specific detection possibilities.

The TOF-SIMS and SEM-EDS seem to be a promising tool to study the impact of environmental pollution on human health. As the data obtained shows, they may both be very useful as they provide supplementary information. The study showed the possibility of existence of exogenous dust particles on the hair surface, containing mainly $\mathrm{Sr}$ and $\mathrm{F}$ particles coming from the dump, transported over the distance. However, more complex studies need to be made in the future.

\section{ACKNOWLEDGED}

The financial support of this work by the Polish Scientific Research Council (grant N207 075 31/3611) is gratefully acknowledged.

\section{LITERATURE CITED}

(1) Chojnacka K., Górecka H., Chojnacki A., Górecki H.: Inter-element interactions in human hair, Environmental Toxicology and Pharmacology 2005, 20, 368.

(2) Rodushkina I., Axelsson M. D.: Application of double focusing sector field ICP-MS for multielemental characterization of human hair and nails. Part I. Analytical methodology, The Science of the Total Environment 2000, 250, 83.

(3) Kempson I. M., Skinner W. M.: ToF-SIMS analysis of elemental distributions in human hair, Science of the Total Environment 2005, 338, 213.

(4) Rutherford P. M., Dudas M. J., Arocena J. M.: Radioactivity and elemental composition of phosphogipsum produced from three phosphate rock sources, Waste Management \& Research 1995, 13, 407. 